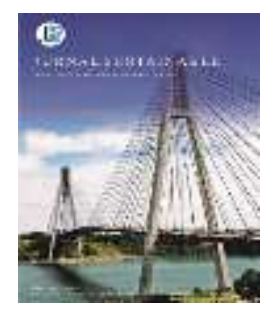

\title{
Prediksi Pasang Surut Air Laut Menggunakan Jaringan Syaraf Tiruan Backpropagation
}

\author{
Nerfita Nikentari ${ }^{1, *}$, Nola Ritha ${ }^{2,}$, Tri Haryadi ${ }^{3}$ \\ 1,2,3 Jurusan Teknik Informatika, Fakultas Teknik, Universitas Maritim Raja Ali Haji \\ ${ }^{1,2,3} \mathrm{Jl}$. Politeknik Senggarang, Tanjungpinang 29100 \\ Corresponding Author: nerfita.nikentari@umrah.ac.id
}

\begin{abstract}
The tide of sea water has an effect on the activities carried out in the sea, namely shipping activities, fishing activities, and loading and unloading of ships, because tidal events occur not at the same time therefore the need for tide level prediction. Tide level data for forecast based historical tide data obtained from BMKG Tanjungpinang from January 1 to February 11,2015 , research was done by using Backpropagation. This study using as many as 1000 high tide data with some input parameters such as max iteration, target error, learning rate, number of input, and update learning rate. The accuracy of this forecast is measured by calculating the average error using MSE (Means Square Error). The best modeling result of Backpropagation with 5 hidden layer and learning rate 0,9 produce the smallest MSE 0,0035861.
\end{abstract}

Keywords - forcast, sea tide, backpropagation

Intisari- Pasang surut air laut mempunyai pengaruh terhadap suatu kegiatan yang dilakukan di laut yaitu kegiatan pelayaran, kegiatan para nelayan, serta bongkar muat kapal, oleh karena kejadian pasang surut terjadi tidak pada waktu yang sama oleh karena itu perlu adanya prediksi pasng surut air laut. Berdasarkan data tunggal ketinggian pasang surut sebelumnya yang diperoleh dari BMKG kota Tanjungpinang dari tanggal 1 Januari sampai dengan 11 Februari 2015, maka dilakukan penelitian dengan menggunakan algoritma Backpropagation Pada penelitian ini menggunakan sebanyak 1000 data tinggi pasang surut dengan beberapa parameter inputan seperti max iterasi, target error, learning rate, jumlah input, dan update learning rate. Pada pengujian ini akan diukur tingkat akurasinya dengan menghitung error rata-rata menggunakan MSE (Means Square Error). Hasil pemodelan terbaik Backpropagation dengan 5 hidden layer, dan nilai learning rate adalah 0,9 menghasilkan nilai MSE 0,0035861.

Kata kunci - prediksi, pasang surut air laut, backpropagation

\section{Pendahuluan}

Laut merupakan suatu bagian dari bumi yang di penuhi oleh air asin, juga dikenal sebagi suatu tempat yang paling banyak memiliki ekosistem kehidupan di dalamnya. Adapun faktor yang berpengaruh besar terhadap kehidupan ekosistem di dalam laut ialah suatu gerakan air laut yang disebut dengan pasang surut. Pasang surut air laut juga mempunyai pengaruh terhadap suatu kegiatan yang dilakukan di laut yaitu kegiatan pelayaran, kegiatan para nelayan, serta bongkar muat kapal. Oleh karena kejadian pasang surut terjadi tidak pada waktu yang sama, maka diperlukan suatu prediksi dengan tujuan agar dapat mengetahui tinggi pasang dan surut air laut yang berguna untuk mengetahui tinggi pasang surut yang akan terjadi dan juga dapat digunakan sebagai acuan 
dalam melakukan suatu kegiatan di perairan laut tersebut.

Penelitian terdahulu terkait prediksi dilakukan dengan mengimplementasi jaringan syaraf tiruan Backpropagation untuk memprediksi cuaca. Dalam penelitian tersebut varibel yang digunakan untuk memprediksi cuaca harian adalah data suhu, kelembaban, dan curah hujan. Penelitian ini menghasil error maksimum sebesar 0.01 dan 0.001 , hasil tersebut diperoleh menggunakan iterasi 15000, 7 hidden layer, dan error maksimum 0.001 dengan hasil aktual yang dapat memprediksi secara tepat sebesar $32.25 \%$ [1].

Jaringan saraf tiruan Backpropagation untuk memprediksi nilai ujian sekolah yang variabel inputnya berupa nilai rapor mata pelajaran Matematika dan IPA serta nilai Ujian Sekolah pada kedua mata pelajaran tersebut telah diterapkan [2]. Hasil penelitiannya menunjukkan bahwa nilai Mean Square Error (MSE) terkecil pada mata pelajaran Matematika diperoleh sebesar 0,5100175 dengan kombinasi parameter pelatihan berupa 26.000 epoch dan learning rate sebesar 0,5. Pada mata pelajaran IPA, nilai MSE terkecil diperoleh sebesar 0,1405143 lewat kombinasi parameter pelatihan 1.000 epoch dan nilai learning rate 0,9 . Tingkat akurasi rata-rata keluaran jaringan diperoleh sebesar $80,15 \%$.

Backpropagation digunakan untuk prediksi cuaca pada beberapa area di Mumbai, India. Penelitian ini menngunakan metode error Backpropagation. Hasil penelitian menunjukkan hasil prediksi dalam range yang dapat diterima [3]. [4] memprediksi distribusi air Perusahaan Air Minum Daerah (PDAM) Kota Malang menggunakan Backpropagation dengan 2 variabel input yaitu jumlah kehilangan air dan air yang dijual. Penelitian ini menggunakan 80 data untuk pelatihan dan 11 data untuk pengujian. Hasil pengujian dengan menggunakan parameter 5 node pada lapisan tersembunyi, nilai learning rate 0,1 dan minimum error 0,00001 menghasilkan jaringan dengan tingkat akurasi $97,99 \%$.

\begin{tabular}{llr}
\multicolumn{1}{c}{ Peramalan terhadap mahasiswa yang } \\
mendaftar & beasiswa & menggunakan \\
Backpropagation & menghasilkan nilai akurasi
\end{tabular}

sebesar 99\%. Variabel yang digunakan pada penelitian adalah IPK, jumlah SKS, status dan pendapatan orang tua. Struktur jaringan adalah 4-25-1, dimana 4 adalah jumlah node pada input, 25 node pada hidden layer dan 1 node pada output layer. Keluaran pada jaringan adalah diterima atau ditolak. Parameter optimum yang diperolah dari hasil pelatihan adalah nilai error terkecil sebesar 0,000101 pada epoch ke 329, learning rate 0,2 dan momentum 0,2. Total data untuk pelatihan dan pengujian adalah 3000 data dengan jumlah data training 2.250 dan jumlah data testing adalah 750 [5].

Penelitian-penelitian sebelumnya menunjukkan Backpropagation memberikan hasil yang cukup baik dalam memprediksi data. Penelitian ini bertujuan memprediksi pasang surut air laut. Data digunakan dalam penelitian ini adalah data pasang surut air laut perjam.

\section{Metode Penelitian}

\section{A. Pengolahan Data}

Data yang digunakan pada penelitian ini adalah data pasang surut air laut per jam dari tanggal 1 Januari 2015 sampai dengan 11 Februari 2015 berjumlah 1000 data, dimana data tersebut dibagi menjadi menjadi 2 bagian yaitu data untuk pelatihan (training) berjumlah 700 data dan data untuk pengujian (testing) berjumlah 300 data. Data pelatihan digunakan khusus untuk proses pelatihan data pasang surut air laut untuk mendapatkan hasil pelatihan, yaitu nilai bobot (weight).

Data-data yang ada akan digunakan dalam prediksi dinormalisasi dengan membagi nilai data tersebut dengan nilai range data (nilai data maksimum - nilai data minimum). Tujuan dari normalisasi adalah (1) untuk menghilangkan kerangkapan data, (2) untuk merubah nilai menjadi satu-satuan, dan (3) untuk mempermudah pemodifikasi data [6]. Fungsi aktifasi yang diguakan dalam jaringan syaraf tiruan pada penelitian ini adalah sigmoid biner (range 0 hingga 1), maka data harus ditransformasi menjadi $[0,1]$. Normalisasi data menggunakan persamaan 1 . 


$$
X_{n}=\frac{X_{0}-X_{\min }}{X_{\max }-X_{\min }}
$$

Denormalisasai merupakan proses pengembalian data, yaitu data kembali ke nilai semula. Adapun persamaan untuk denormalisasi dapat dilihat dalam persamaan 2 :

$$
X_{i}=y\left(X_{\max }-X_{\min }\right)+X_{\min }
$$

Dimana :

$X_{n} \quad=$ Nilai data normal

$X_{0} \quad=$ Nilai data aktual

$X_{\min }=$ Nilai minimum data aktual keseluruhan

$X_{\max }=$ Nilai maksimum data aktual

keseluruhan.

Dikarenakan penelitian ini menghasilkan suatu ramalan maka perlu diketahui besarnya kesalahan peramalan. Mean Square Error (MSE) merupakan metode yang digunakan untuk menyatakan besarnya kesalahan rata-rata kuadrat dari suatu metode peramalan [7] dengan persamaan :

$$
M S E=\frac{\sum_{t=1}^{n} e_{t}^{2}}{n}
$$

Dimana :

$n:$ jumlah data

$e_{t}$ : nilai kesalahan hasil ramalan yang diperoleh dari $X_{t}-\hat{X}_{t}$ dalam hal ini $X_{t}$ adalah nilai data aktual dan $\hat{X}_{t}$ adalah nilai ramalan.

Inisialisasi bobot awal pada jaringan diperoleh dengan menggunakan metode Nguyen-Widrow. Metode ini menginisialisasi bobot-bobot lapisan dengan nilai antara 0 sampai 1[8]. Metode Nguyen-Widrow dapat diimplementasikan dengan prosedur sebagai berikut.

Tetapkan :

$\mathrm{n}=$ jumlah neuron pada lapisan input

$\mathrm{P}=$ jumlah neuron pada lapisan tersembunyi.

$\beta=$ faktor penskalaan $\left(=0,7(p)^{1 / n}\right.$

kerjakan untuk setiap unit pada lapisan tersembunyi $(j=1,2, \ldots p)$ :

a. Inisialisasi bobot-bobot dari lapisan input ke lapisan tersembunyi :
$\mathrm{V}_{\mathrm{ij}}$ bilangan random antara 0 sampai 1 (atau antara $-\gamma$ sampai $\gamma$ ).

b. Hitung $\left\|\mathrm{V}_{\mathrm{j}}\right\|$

Dimana

||$V_{j}||=\sqrt{\left(V_{1 j}^{2}\right)+\left(V_{2 j}\right)^{2}+\cdots\left(V_{n j}\right)^{2}}$

c. Inisialisasi ulang bobot-bobot :

$V_{i j}=\frac{\beta V_{i j}}{|| V_{j} \|}$

d. Set bias :

$\mathrm{b} 1_{\mathrm{j}}=$ bilangan random antara $-\beta$ sampai $\beta$.

Analisa Nguyen-Widrow didasarkan atas fungsi aktivasi tangen hiperbolik.

Fungsi aktivasi yang dapat digunakan dalam metode propagasi balik antara lain adalah sigmoid biner, sigmoid bipolar, dan tange hiperbolik. Fungsi aktivasi pada jaringan sayaraf tiruan harus berkarakteristik kontinu, diferensiabel, dan tidak menurun secara monoton [ 9]. Penelitian ini menggunakan fungsi aktivasi sigmoid biner. Fungsi aktivasi ini memiliki range $(0,1)$ dan didefinisikan sebagai:

$$
f_{1}(x)=\frac{1}{1+e^{-x}}
$$

Dengan turunan:

$$
f_{1}(x)=f_{1}(x)\left(1-f_{1}(x)\right)
$$

Fungsi sigmoid biner ini digambarkan pada Gambar 1.

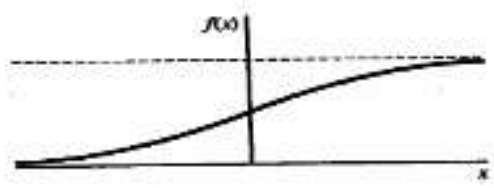

Gambar 1. Fungsi sigmoid biner dengan range $(0,1)$

\section{B. Arsitektur Jaringan Syaraf Tiruan}

Arsitektur dari jaringan syaraf tiruan Backpropagation untuk prediki pasang surut air laut dapat dilihat pada Gambar 2. Data input jaringan ada 5 yang merepresentasikan jumlah masukan 5 variabel input berupa data pasang surut air laut pada jam-jam sebelumnya (xt-1, xt2 , xt-3,xt-4) data pasang surut sekarang (xt) dan data data pasng surut pada jam berikutnya 
$(\mathrm{xt}+1)$ untuk variabel output. Jumlah hidden node pada jaringan adalah 5 .

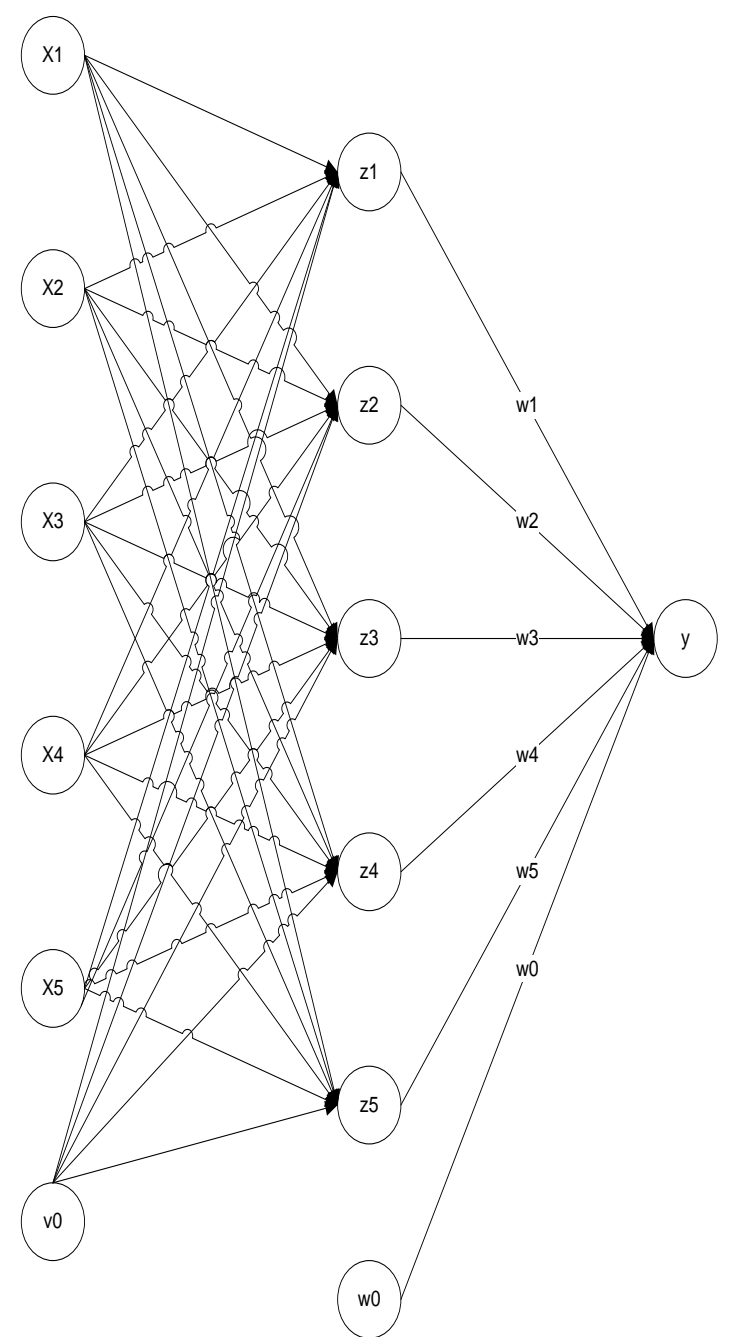

Gambar 2. Arsitektur Jaringan Syaraf Tiruan Backpropagation Prediksi Pasang Surut Air Laut

\section{Hasil dan PeMbahasan}

\section{A. Pemodelan Data}

Untuk membangun model dengan mendapatkan hasil prediksi yang akurat prediksi pasang surut air laut ini dilakukan pelatihan berkali-kali untuk mencari hasil terbaik. Proses pelatihan dapat dilihat pada Gambar 3.

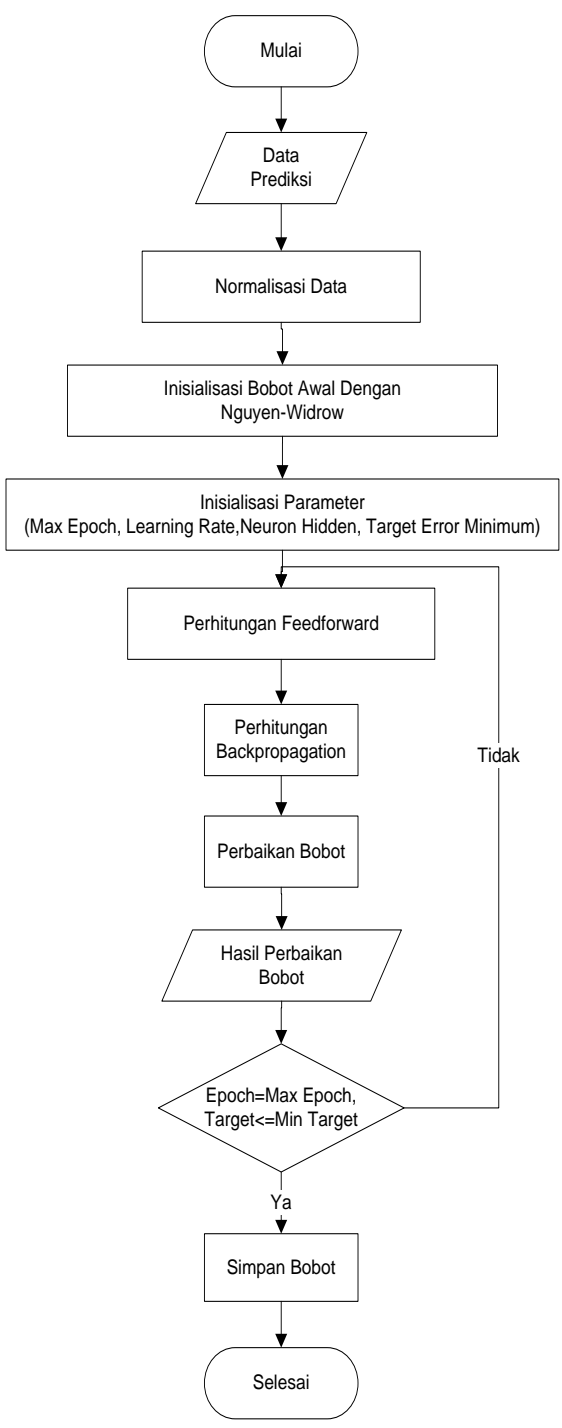

Gambar 3. Flowchart Pelatihan Jaringan Syaraf Tiruan Backpropagation Prediksi Pasang Surut Air Laut

Hasil pelatihan pada Backpropagation untuk mendapatkan nilai parameter terbaik dapat dilihat pada Tabel 1 .

Tabel 1. Pelatihan Jaringan Syaraf Tiruan

\begin{tabular}{|c|c|c|c|}
\hline No & Hidden Node & Learning Rate & MSE \\
\hline 1 & 3 & 0,1 & 0,0092612 \\
\hline 2 & 3 & 0,2 & 0,0076365 \\
\hline 3 & 3 & 0,3 & 0,0083759 \\
\hline 4 & 4 & 0,4 & 0,0088378 \\
\hline 5 & 4 & 0,5 & 0,0078104 \\
\hline 6 & 4 & 0,6 & 0,0078311 \\
\hline 7 & 5 & 0,7 & 0,0043019 \\
\hline 8 & 5 & 0,8 & 0,0095528 \\
\hline 9 & 5 & 0,9 & 0,0035861 \\
\hline 10 & 3 & 0,01 & 0,0098618 \\
\hline 11 & 3 & 0,02 & 0,0096817 \\
\hline
\end{tabular}




\begin{tabular}{|l|l|l|l|}
\hline 12 & 3 & 0,03 & 0,0095481 \\
\hline 13 & 4 & 0,04 & 0,0098058 \\
\hline 14 & 4 & 0,05 & 0,0096463 \\
\hline 15 & 4 & 0,06 & 0,0094455 \\
\hline 16 & 5 & 0,07 & 0,0089112 \\
\hline 17 & 5 & 0,08 & 0,0094493 \\
\hline 18 & 5 & 0,09 & 0,0088518 \\
\hline
\end{tabular}

Adapun parameter yang digunakan setelah dilakukan berbagai percobaan saat proses pelatihan jaringan maka konfigurasi model terbaik adalah sebagai berikut :

$\begin{array}{ll}\text { Target } \text { error } & : 0,01 \\ \text { Learning Rate } & : 0,9 \\ \text { Hidden node } & : 5\end{array}$

\section{B. Hasil Pengujian}

Setelah mendapatkan parameter terbaik selanjutnya dilakukan pengujian pada jaringan. Flowchart proses pengujian pada jaringan dapat dilihat pada Gambar 4.

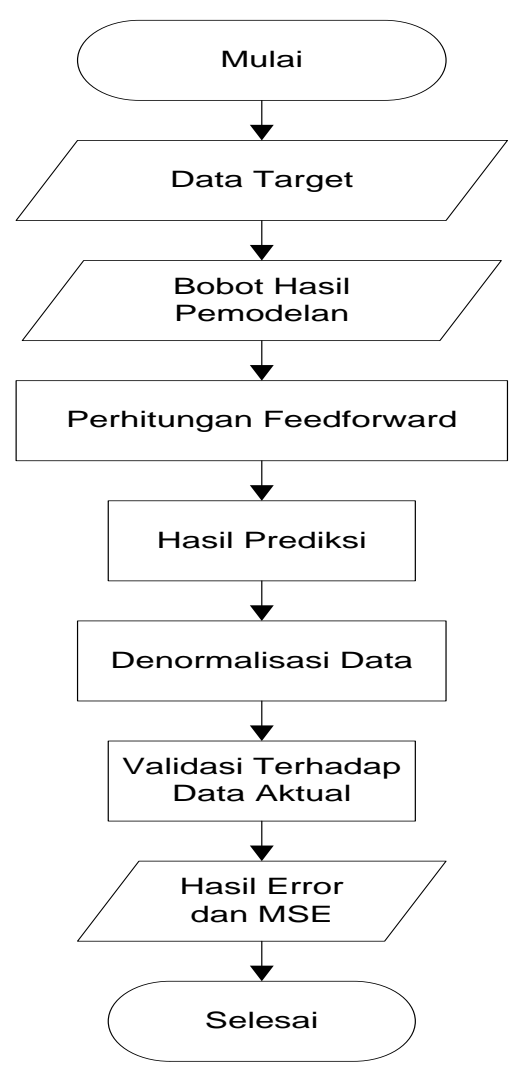

Gambar 4. Flowchart Pegujian Jaringan Syaraf Tiruan

Hasil pengujian (testing) prediksi dapat dilihat pada tabel 1 . Hasil prediksi memperlihat perbandingan data asli (target) dengan data hasil prediksi dengan jaringan syaraf tiruan Backpropagation.

Tabel 2. Hasil Prediksi

\begin{tabular}{|c|c|c|c|}
\hline $\begin{array}{c}\text { Data } \\
\text { ke }\end{array}$ & $\begin{array}{c}\text { Target } \\
(\mathrm{m})\end{array}$ & Prediksi $(\mathrm{m})$ & Error \\
\hline 1 & 0,6 & 0,5847284 & 0,0152715 \\
\hline 2 & 0,7 & 0,6764011 & 0,0235988 \\
\hline 3 & 0,8 & 0,8141145 & 0,0141145 \\
\hline 4 & 1 & 0,9868353 & 0,0131646 \\
\hline 5 & 1,2 & 1,1931456 & 0,0068543 \\
\hline 6 & 1,4 & 1,3766006 & 0,0233993 \\
\hline 7 & 1,5 & 1,5094158 & 0,0094158 \\
\hline 8 & 1,6 & 1,5626682 & 0,0373317 \\
\hline 9 & 1,6 & 1,5661725 & 0,0338274 \\
\hline 10 & 1,6 & 1,5391347 & 0,0608652 \\
\hline$:$ & $:$ & & $:$ \\
\hline 296 & 1,2 & 1,2200744 & 0,0200744 \\
\hline 297 & 1,3 & 1,3343035 & 0,0343035 \\
\hline 298 & 1,3 & 1,3930856 & 0,0930856 \\
\hline 299 & 1,3 & 1,3914814 & 0,0914814 \\
\hline 300 & 1,3 & 1,3487020 & 0,0487020 \\
\hline & $\mathrm{MSE}$ & & 0,00794940 \\
\hline & & & \\
\hline & & $:$ & \\
\hline & & & \\
\hline
\end{tabular}

\section{KESIMPULAN}

Prediksi pasang surut air laut menggunakan jaringan syaraf tiruan Backpropagation yang menggunakan 700 data latih dan 300 data uji menghasilkan nilai MSE 0,0079440. Hasil ini didapatkan dengan menggunakan pemodelan jaringan yaitu 5 node pada jaringan tersembunyi, nilai error target 0,01 dan nilai learning rate adalah 0,9 .

\section{REFERENSI}

[1] S.A.F. Haryanto, Ernawati, dan P. Diyah, "Implementasi Jaringan Syaraf Tiruan Backpropagation Untuk Memprediksi Cuaca", Jurnal Rekursif, Vol 3, No (2), November 2015.

[2] S. Kosasi, "Penerapan metode jaringan saraf tiruan backpropagation untuk memprediksi nilai ujian sekolah", Jurnal Teknologi, Vol 7, No (1), Juni 2014.

[3] N. Meera, F. Priyanca dan Debajyoti. Mukhopadhyay, "Weather Forecasting 
Using ANN with Error Backpropagation Algorithm", Proceedings of the International Conference on Data Engineering and Communication Technology. Advances in Intelligent Systems and Computing, vol 468. Springer, Singapore.

[4] D. Jauhari, A. Himawan, dan C. Dewi, "Prediksi Distribusi Air PDAM Mengguakan Metode Jaringan Syaraf Tiruan Backpropagation di PDAM Kota Malang, Jurnal Teknologi Informasi dan Ilmu Komputer, Vol 3, No (2), Juni 2016.

[5] A. Pujianto, K. Kusrini, dan A. Sunyoto, "Perancangan Sistem Pendukung Keputusan Untuk Prediksi Penerima Beasiswa Menggunakan Metode Neural
Network Backpropagation", Jurnal Teknologi Informasi dan Ilmu Komputer, Vol 5, No (2), Mei 2018.

[6] R. Hidayat dan Supratpto, "Meminimalisasi Nilai Error Peramalan Dengan Algoritma Extreme Learning Mechine", Jurnal Optimasi Sistem Industri, Vol 11, No (1), 187-192.

[7] S. Hansun, "Penerapan WEMA Dalam Peramalan Data IHSG", Ultimatics, Vol 5, No (2), Desember 2013.

[8] S. Kusumadewi dan S. Hartati, "NeuroFuzzy Integrasi Sistem Fuzzy dan Jaringan Syaraf Tiruan", Graha Ilmu, Yogyakarta

[9] D. Puspitaningrum, Pengantar Jaringan Syaraf Tiruan, Andi, Yogyakarta, 2009. 